\title{
Análise das características físicas e propriedades mecânicas de argamassa com inserção de resíduos de madeira
}

\author{
Analysis of the physical characteristics and \\ mechanical properties of the coating mortar \\ with the insertion of wood residues
}

\author{
Jussara Adílio da Silva ${ }^{1}$, Jorge Henrique Piva ${ }^{1}$, Augusto Wanderlind ${ }^{1}$, \\ Aline Eyng Savi ${ }^{1}$, Elaine Guglielmi Pavei Antunes ${ }^{1}$
}

\footnotetext{
${ }^{1}$ Universidade do Extremo Sul Catarinense, UNESC, Departamento de Engenharia Civil, Grupo de Pesquisa em Desempenho de Estruturas e Construção Civil, GPDECC, Avenida Universitária, 1105, CEP: 88806-000, Criciúma, Santa Catarina, Brasil.

E-mail: juuussara@hotmail.com,jhpiva@gmail.com,acw@unesc.net, arquiteta.alinesavi@gmail.com, elainegpa@unesc.net
}

\section{RESUMO}

A madeira, além de ser um material renovável, possui diversas propriedades que a torna muito atraente frente a outros materiais, dentre as quais, destaca-se as boas características de isolamento térmico. Tendo em vista que a construção civil é um setor com um elevado consumo de recursos naturais, qualquer ação proposta para diminuir impactos da construção civil sobre o meio ambiente contribui para o desenvolvimento sustentável. Este trabalho consiste em substituir o agregado miúdo por resíduo de madeira em argamassa e analisar suas características físicas e propriedade mecânicas. O traço utilizado no estudo como referência foi de 1:5 (cimento: areia), em massa, e adotou-se um percentual de substituição de 0, 2,5, 5,0 e 10,0\%. Para ser utilizado na mistura, o resíduo de madeira foi submetido a um tratamento químico. Posteriormente verificou-se sua influência nos ensaios de índice de consistência, determinação da retenção de água e densidade de massa no estado fresco e absorção de água por capilaridade, coeficiente de capilaridade, massa específica real, índice de vazios, resistência a tração na flexão e compressão axial no estado endurecido. Além destes, realizou-se também um ensaio a fim de se obter uma análise comparativa entre as composições acerca a capacidade de isolamento térmico de cada uma. Com base nos resultados obtidos constata-se que as características das argamassas com substituição do agregado miúdo por resíduo de madeira, indiferente ao percentual de substituição, apresentaram valores positivos nas características reológicas da argamassa e no estado endurecido quase semelhantes à argamassa sem inserção do resíduo. Em relação ao ensaio de isolamento térmico todas as composições com resíduo de madeira apresentaram um melhor resultado quando comparado com a mistura de referência.

Palavras-chave: resíduo de madeira; argamassa; conforto térmico; sustentabilidade.

\section{ABSTRACT}

Wood, besides being a renewable material, has several properties that make it very attractive compared to other materials, among which the good thermal insulation characteristics stand out. Since civil construction is a sector with a high consumption of natural resources, any action proposed to reduce the impact of civil construction on the environment contributes to sustainable development. This work consists in replacing the small aggregate with wood waste in air-games and analyze its physical characteristics and mechanical property. The trace used in the study as reference was 1:5 (cement: sand), in mass, and a substitution percentage of $0,2.5,5.0$ and $10.0 \%$ was adopted. To be used in the mixture, the wood residue was submitted to a chemical treatment. Afterwards, its influence was verified in the consistency index tests, determination of water retention and mass density in the fresh state and water absorption by capillarity, capillarity coefficient, real specific mass, void index, tensile strength in bending and axial compression in the hardened-cido state. Besides these, a test was also performed in order to obtain a comparative analysis between the com-positions about the thermal insulation capacity of each one. Based on the results obtained, it was found that the charac- 
teristics of the mortars with substitution of the small aggregate for wood residue, indifferent to the percentage of substitution, showed positive values in the rheological characteristics of the mortar and in the hardened state almost similar to the mortar without residue insertion. Regarding the thermal insulation test, all compositions with wood residue showed a better result when compared with the reference mixture.

Keywords: wood residue; mortar; thermal comfort; sustainability.

\section{INTRODUÇÃO}

A construção civil é um setor com elevado consumo de recursos naturais, sendo que o problema das questões ambientais e o elevado consumo de recursos naturais estão presentes de forma acentuada [1, 2]. Qualquer ação proposta para diminuir impactos da construção civil sobre o meio ambiente contribui para o desenvolvimento sustentável. Para suprir a necessidade dos usuários é preciso buscar materiais para a construção de edificações mais eficientes [3]. O uso de resíduos de madeira pela indústria da construção civil auxilia nesta busca por um desenvolvimento sustentável, pois atua na redução do custo dos materiais de construção, poupa matéria-prima natural, além de proteger o meio ambiente [2].

Em qualquer lugar do mundo gera-se anualmente enormes quantidades de resíduos de madeira, cuja disposição inadequada pode levar a danos ambientais e preocupações econômicas para as empresas madeireiras [4-6]. Conforme BITENCOURT et al. [7] seria irracional não promover o máximo aproveitamento destes subprodutos oriundos da indústria madeireira. $\mathrm{O}$ uso de resíduos de madeira trata-se de uma solução para a crescente quantidade de resíduos gerada e pode promover uma prática de gestão de resíduos que ajuda a mitigar o efeito destes sobre o ambiente, promovendo assim uma prática ambiental sustentável e verde, especialmente nos países em desenvolvimento [6, 8].

No Brasil, segundo a Associação Brasileira da Indústria de Madeira Processada Mecanicamente (ABIMCI) [9] em 2016 a produção de madeira serrada no país ficou próxima de 10,0 milhões de $\mathrm{m}^{3}$ e conforme dados da Indústria Brasileira de Árvores (IBÁ) [10] em 2018 a produção brasileira de madeira serrada ficou em 9,1 milhões de $\mathrm{m}^{3}$, sendo que, com este desempenho, o Brasil ocupa o $8^{\circ}$ lugar entre os principais países produtores de madeira serrada do mundo.

O aproveitamento de uma tora de madeira em tábuas se dá na ordem de $40 \%$, sendo que, os $60 \%$ restantes caracterizam-se como resíduos (10\% resíduos de plaina, 26\% resíduos do corte, 11\% casca e $13 \%$ pó de serra, além das perdas devido à presença dos defeitos) [11]. E, durante o beneficiamento da madeira, de acordo com CADORIN [12], a quantidade de resíduo a ser gerada pode chegar a $25 \%$.

A NBR 10004 [13] classifica os resíduos sólidos quanto aos seus potenciais ao meio ambiente e à saúde pública, para que possam ser gerenciados adequadamente. A madeira é classificada como: Resíduos Classe II - Não Inertes, podem ter propriedades como: biodegradabilidade, combustibilidade ou solubilidade em água. Os resíduos de madeira são classificados por WIECHETECK [14] como serragem, cepilho, sólidos de madeira, cascas e outros e são gerados desde o transporte da madeira em tora à indústria, até seu manuseio e processamento, finalizado no produto acabado.

A madeira, além de ser um material renovável, possui diversas propriedades que a torna muito atraente frente a outros materiais, dentre os quais, destaca-se as boas características de isolamento térmico [15]. O desenvolvimento de materiais de construção com baixa condutividade térmica com uso de subprodutos da madeira é uma alternativa interessante que pode ajudar a resolver simultaneamente preocupações energéticas e ambientais [4], principalmente quando se relaciona as necessidades de desempenho das edificações. Conforme OLIVEIRA [16] "O conforto térmico se compõe das condições ambientes nos quais o usuário apresenta ótimos níveis de saúde, conforto e desempenho de suas atividades”. A NBR 15575-1 [17] estabelece requisitos mínimos de desempenho acústico, térmico, de iluminação, hidráulico, dentre outros. Para COTA [18], o isolamento térmico adequado permite minimizar as trocas térmicas excessivas entre o interior e o exterior de um edifício, ou seja, reduzir as perdas de calor no inverno e o sobreaquecimento interior no verão, o que conduz a uma redução dos custos associados ao aquecimento e resfriamento.

O uso de resíduos lignocelulósicos dentro de matriz de cimento tem sido estudado devido ao aspecto renovável destes recursos vegetais e as qualidades térmicas e acústicas do material cimentício leve obtido [2, $19,20]$. Utilizar resíduo de madeira em substituição a areia na produção de argamassa, a princípio, parece algo desnecessário, mas ao fazer-se uma análise baseada em regras normativas, o resultado pode ser positivo e, sobretudo, ser economicamente viável [21, 22]. A utilização de resíduos de madeira para a produção de argamassas menos densas tornou-se uma questão importante nos últimos anos, principalmente em países tropicais [6].

Estudos com inserção de resíduos de madeira adicionados em argamassas sem qualquer tratamento 
preliminar, reduz a densidade da argamassa, bem como condutividade térmica $[2,4,23,24]$. No entanto, o tratamento destes materiais antes da sua incorporação na matriz é muitas vezes necessário para reduzir a sua absorção de água, além de melhorar as propriedades mecânicas do composto e, ainda, preservar as qualidades isolantes $[2,25]$.

As substâncias presentes na madeira como hemiceluloses, amidos, açúcares, fenóis, entre outros extrativos, podem inibir o processo de hidratação do cimento e, por conseguinte, alterar as características reológicas no estado fresco, as características físicas e as propriedades mecânicas no estado endurecido das argamassas [26]. Além disso, segundo IZQUIERDO [27] a madeira, por ser de origem vegetal, tem sua durabilidade comprometida quando inserida em matrizes cimentícias, principalmente pelo caráter alcalino da referida matriz. Outro ponto, ainda mencionado pelo mesmo autor, refere-se a maior absorção de água, porosidade e menor massa específica do resíduo de madeira, em comparação à areia, que pode comprometer a resistência mecânica da mistura cimentícia. Contudo, tais características podem ser atenuadas com tratamentos químicos, conforme já realizado por MOUBARICK, GRIMI e BOUSSETA [28], VILPERT [29], PELLEGRIN [30], AIGBOMIAN e FAN [8] e TITA, PAIVA e FROLLINI [31]. Segundo VILPERT [29] o processo remove um percentual de lignina, ceras e óleos da superfície do resíduo de madeira e, assim, aumenta a rugosidade, proporciona melhor aderência entre os materiais, diminui a porosidade e atenua a interferência na hidratação da matriz cimentícia.

A presente pesquisa tem como objetivo analisar as características físicas e as propriedades mecânicas de argamassa com substituição parcial do agregado miúdo por resíduo de madeira.

\section{MATERIAIS E MÉTODOS}

Os resíduos de madeira utilizados na pesquisa foram coletados em uma madeireira da Região Sul de Santa Catarina e são provenientes de madeiras da espécie Pinus Elliottii e Eucalyptus Grandis. Após coletados, os resíduos foram submetidos a uma secagem em estufa com temperatura de $100{ }^{\circ} \mathrm{C}$ por um período de $24 \mathrm{~h}$ para eliminação da umidade superficial. Posteriormente, eles passaram por tratamento com a função de solubilização da hemicelulose e da lignina.

O procedimento consistiu na imersão do resíduo em uma solução de $15 \%$ de $\mathrm{NaOH}$ que foi aquecida através de banho-maria durante um período de $90 \mathrm{~min}$. Em seguida, o resíduo foi lavado com água em abundância para, por fim, ser seco em estufa por $48 \mathrm{~h}$ a $30^{\circ} \mathrm{C}$. Tal tratamento foi fundamentado principalmente em Moubarick, GRIMI e BOUSSETA [28]. A Figura 1a ilustra o resíduo de madeira na solução alcalina e a Figura $1 \mathrm{~b}$ o resíduo após o procedimento.

a)

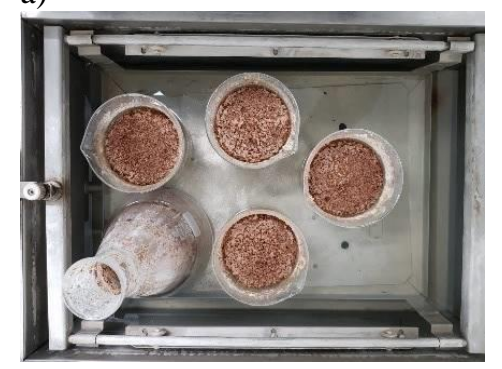

b)

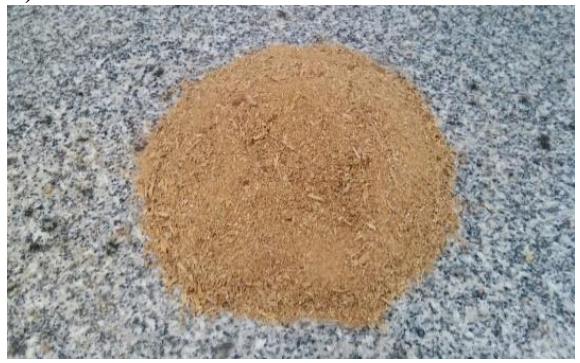

Figura 1: (a) Resíduo de madeira durante tratamento químico, (b) Resíduo de madeira após o tratamento químico.

Para elaboração do traço da argamassa foram utilizados Cimento CP II-Z da classe 32 e areia como agregado miúdo, com traço de 1:5 (cimento: areia) em massa. Optou-se por um traço de cimento e areia fundamentado nos trabalhos de GUPTA, KUA e KON [32], GIL, ORTEGA e PÉREZ [6], CORINALDESI, MAZZOLI e SIDDIQUE [4] e ACIU, TAMAS-GAVREA e MUNTEANU [33], tendo em vista que todos estes autores pesquisaram a inserção de resíduos de madeira em argamassas. A partir do traço unitário em massa, foi obtido o traço unitário em volume, através da massa unitária do agregado miúdo. A relação aglomerante/agregados manteve-se constante, a fim de não afetar a resistência mecânica da mistura.

O percentual de substituição do agregado miúdo por resíduo de madeira foi definido com base na pesquisa realizada por Corinaldesi, Mazzoli e Siddique [4], no qual foram utilizados três valores diferentes de substituição, 2,5, 5,0 e 10,0\% em relação ao volume do agregado miúdo. As amostras foram codificadas de acordo com o percentual de substituição, por exemplo, ARM2,5 (argamassa com substituição do agregado 
miúdo pelo resíduo de madeira em 2,5\%). A AREF refere-se a argamassa referência - sem inserção de resíduo de madeira.

A Tabela 1 apresenta os traços unitários utilizados para a mistura da argamassa com suas respectivas substituições feitas a partir do volume do agregado miúdo.

Tabela 1: Traços unitários em massa e em volume.

\begin{tabular}{cccc}
\hline Traço & Cimento $(\mathrm{kg})$ & Areia $(\mathrm{kg})-\left(\mathrm{dm}^{3}\right)$ & Resíduo de madeira $(\mathrm{kg})-\left(\mathrm{dm}^{3}\right)$ \\
\hline AREF & 1 & $5,00-3,09$ & $0,00-0,00$ \\
ARM2,5 & 1 & $4,88-3,01$ & $0,02-0,08$ \\
ARM5,0 & 1 & $4,76-2,94$ & $0,03-0,16$ \\
ARM10,0 & 1 & $4,50-2,78$ & $0,06-0,31$ \\
\hline
\end{tabular}

Foi realizado ensaio de composição granulométrica do resíduo de acordo com a NBR NM 248 [34] no qual se obteve um módulo de finura de 2,42 e dimensão máxima característica de 2,4 mm. O ensaio de massa unitária seguiu as diretrizes da NBR NM 45 [35], obtendo-se uma massa unitária de 0,20 kg/dm³ Os mesmos ensaios de caracterização física foram realizados para o agregado miúdo, em que se obteve um módulo de finura de 2,39, diâmetro máximo de 2,40 mm e massa unitária de $1,62 \mathrm{~kg} / \mathrm{dm}^{3}$.

Para definir-se a relação água/cimento dos traços utilizou-se como balizador o ensaio de índice de consistência, conforme a NBR 16541[36] e a NBR 13276 [37], que recomendam, no caso de falta de informação quanto a quantidade de água da mistura da argamassa, adotar a água necessária para obtenção do índice de consistência de $(260 \pm 5) \mathrm{mm}$. Assim sendo, realizou-se o ensaio de índice de consistência com o traço de referência, AREF, adicionando-se água até chegar-se ao valor de consistência de $(260 \pm 5) \mathrm{mm}$. Posteriormente, adotou-se a mesma quantidade de água para todas as composições. Com a relação água/cimento de todos os traços definida, mediu-se o índice de consistência das outras composições.

A mistura da argamassa seguiu as diretrizes da NBR 16541[36] e a determinação do índice de consistência foi realizado conforme a NBR 13276 [37], como já mencionado. O ensaio de retenção de água foi realizado de acordo com a NBR 13277 [38] e o ensaio de densidade de massa segundo a NBR 13278 [39], ambos no estado fresco.

Os ensaios realizados no estado endurecido foram: resistência à tração na flexão, resistência à compressão, absorção de água por capilaridade, coeficiente de capilaridade, massa específica e índice de vazios.

Para os ensaios de resistência à tração na flexão e absorção de água por capilaridade foram moldados três corpos de prova prismáticos de $4 \times 4 \times 16 \mathrm{~cm}$ para cada ensaio e mistura de traço definido, como prescreve respectivamente, a NBR 13279 [40] e a NBR 15259 [41]. Para todos os corpos de prova moldados obedeceu-se a um tempo de cura em condições de laboratório, com temperatura do ar de $(23 \pm 2){ }^{\circ} \mathrm{C}$ e umidade relativa do ar de $(60 \pm 5) \%$, de 28 dias conforme preconiza a NBR 13279 [40]. Foram utilizadas as metades dos três corpos de prova do ensaio de tração na flexão para o ensaio de resistência à compressão axial [41]. O ensaio de massa específica real da argamassa foi realizado como preconiza a NBR 9778 [42], com dois corpos de prova, quantidade mínima especificada pela referida normativa, cilíndricos de $10 \mathrm{~cm}$ de altura e $5 \mathrm{~cm}$ de diâmetro para cada mistura de traço.

A fim de realizar uma análise comparativa entre as composições (AREF, ARM2,5, ARM5,0 e ARM10,0) acerca a capacidade de isolamento térmico de cada uma, realizou-se um ensaio empírico ao qual mediu-se a temperatura na face interna, exposta a uma temperatura elevada, e a temperatura na face externa, exposta a temperatura ambiente, por um determinado período de tempo. Para tal, moldaram-se para cada mistura painéis com dimensões de 48,00 x 48,00 x 4,50 cm (largura x altura x espessura) que foram instalados na abertura de estufa. As dimensões dos painéis foram definidas com base nas dimensões de abertura da estufa, com o intuito de prover um melhor encaixe dos painéis no equipamento. Portanto, as medidas dos painéis (largura x altura x espessura) seguiram as medidas da porta da estufa, que foi retirada para execução do ensaio, considerando $1,00 \mathrm{~cm}$ de folga para cada lado, que foi preenchido com lã de rocha. Após a instalação dos painéis na estufa a mesma era programada na temperatura padronizada de $45 \pm 5{ }^{\circ} \mathrm{C}$ por um período de 4 h, após chegar na referida temperatura.

Para a composição das fôrmas dos painéis, utilizou-se chapas de madeiras compensadas resinadas com espessura de $6 \mathrm{~mm}$. Os painéis foram mantidos por um tempo de cura de 28 dias em condições de laboratório. Durante o ensaio foram realizadas medições de temperatura por meio de quatro termopares do tipo K, calibrados e aferidos no início de cada teste. O Termopar 1 foi instalado no interior da estufa, o Termopar 2 na 
superfície interna do painel, o Termopar 3 na superfície externa do painel e o Termopar 4 no ambiente de laboratório. A temperatura ambiente foi mantida através de refrigerador de ar e manteve-se constante em (23 $\pm 2)^{\circ} \mathrm{C}$ com umidade relativa do ar de $(60 \pm 5) \%$. O controle da temperatura foi registrado pelo software PicoLog, com coleta de dados a cada 5 min.

A Figura 2a apresenta os painéis executados e a Figura $2 \mathrm{~b}$ ilustra a estufa com o painel instalado durante a execução do ensaio.

a)

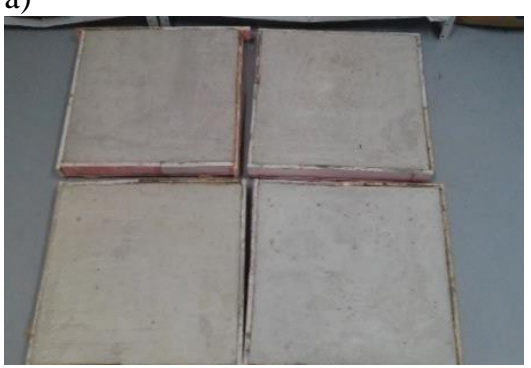

b)

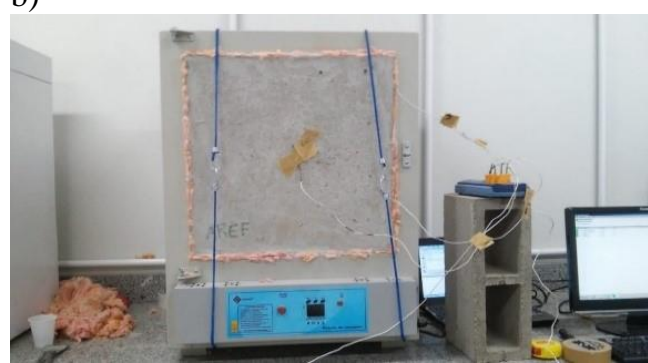

Figura 2: (a) Painéis moldados, (b) Estufa com painel e equipamentos de medição instalados.

A fim de analisar estatisticamente os resultados obtidos nos ensaios foi empregada a Análise de Variância de fator único (ANOVA) e Teste Tukey, ambos com 95\% de significância. A ANOVA foi adotada para analisar os resultados dos ensaios de índice de consistência, absorção de água por capilaridade, coeficiente de capilaridade, massa específica, índice de vazios, resistência à compressão e tração na flexão.

\section{RESULTADOS E DISCUSSÃO}

Para obter-se o índice de consistência recomendado pela NBR 13276 [37] e pela NBR 16541[36] de (260 \pm 5) $\mathrm{mm}$ do traço de referência, AREF, a relação água/cimento encontrada foi de 0,71 . Portanto, a mesma relação água/cimento de 0,71 foi adotada para as composições restantes, ou seja, com substituição do agregado miúdo pelo resíduo de madeira. O gráfico da Figura 3 apresenta os resultados do respectivo ensaio.

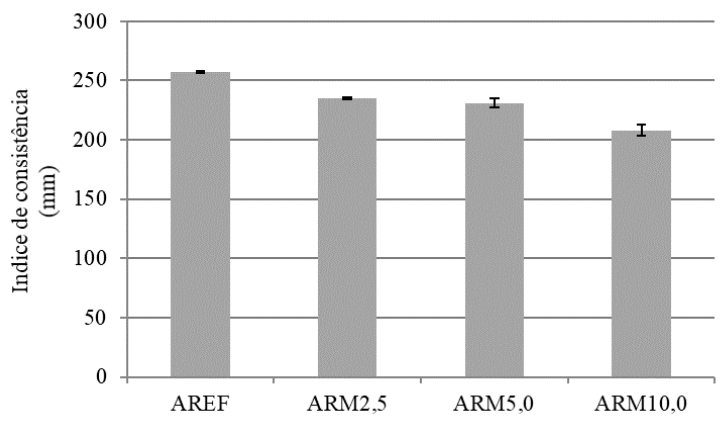

Figura 3: Índice de consistência médio das argamassas.

Como pode ser visualizado na Figura 3 o índice de consistência das argamassas foi diminuindo à medida que o percentual de resíduo de madeira nas misturas foi aumentando. Aplicando-se a Análise de Variância (ANOVA) pode-se afirmar com $95 \%$ de confiabilidade que os resultados apresentaram diferenças significativas entre si, ou seja, a inserção da serragem de madeira influenciou nos resultados de índice de consistência. No entanto, cabe mencionar que todas as composições apresentaram valor acima de $200 \mathrm{~mm}$ e, segundo FORMOSA et al. [43], o índice de consistência próximo de $200 \mathrm{~mm}$ garante consistência e funcionalidade adequadas para aplicações de argamassas.

O comportamento das argamassas quanto à retenção de água no seu estado fresco está apresentado no gráfico da Figura 4 e os resultados da determinação da densidade de massa na Figura 5. 


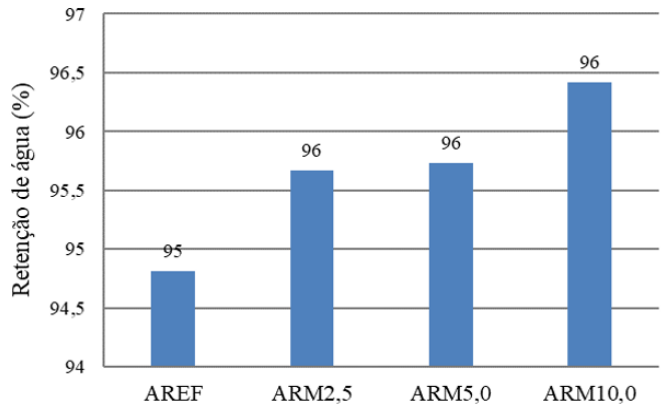

Figura 4: Retenção de água das argamassas no estado fresco.

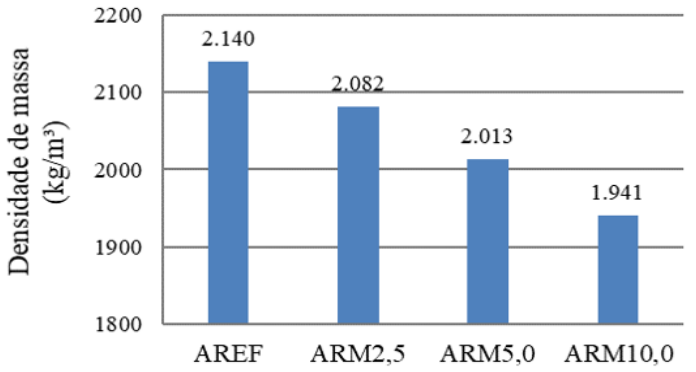

Figura 5: Densidade de massa das argamassas no estado fresco.

Segundo CINCOTTO et al [44] a retenção de água é a capacidade que a argamassa tem, no estado fresco, de manter sua consistência, mesmo em situações propícias à perda de água. FERRARI et al [45] afirmam que a água tem influência direta na trabalhabilidade e na viscosidade da argamassa, tendo papel fundamental nas reações químicas de hidratação do aglomerante. Na determinação da retenção de água foi possível verificar que ao aumentar o percentual de substituição do agregado miúdo por serragem de madeira, aumentou-se levemente a retenção de água da argamassa, apesar de, após o arredondamento dos valores para números inteiros, as composições com resíduo de madeira apresentaram o valor constante de $96 \%$. Tal fato pode ser explicado devido a água "excedente" da mistura ter sido succionada pelos resíduos de madeira. O resíduo de madeira é poroso e quando foi misturado aos outros componentes estava seco, portanto, é provável que ele tenha succionado a água da mistura e, consequentemente, diminuído a quantidade de água livre entre os grãos. Sendo assim, quanto maior o percentual de resíduo de madeira na argamassa, menor a quantidade de água livre na argamassa e, por conseguinte, valores mais altos no ensaio de retenção de água da argamassa no estado fresco. Essa análise coincide com os resultados obtidos no ensaio de índice de consistência, pois, também demonstraram que quanto maior o percentual do resíduo de madeira menor a fluidez da mesma.

Com relação ao ensaio de densidade de massa é possível perceber um declínio nos valores obtidos, ou seja, a argamassa se tornou mais leve à medida em que se aumentou a porcentagem de substituição do agregado miúdo por resíduo de madeira. Tal fato já era esperado, tendo em vista, que se fez a substituição de um material mais denso, areia média quartzosa, com massa específica de aproximadamente $2,64 \mathrm{~g} / \mathrm{cm}^{3}$, pelo resíduo de madeira com massa específica de aproximadamente $1,28 \mathrm{~g} / \mathrm{cm}^{3}$, dados estes apresentados por LIMA e IWAKIRI [46]. Portanto, quanto maior o teor de substituição, menores os valores de densidade de massa. de massa.

No ensaio de determinação da absorção de água por capilaridade foi medido para cada corpo de prova sua massa inicial (m0), sua massa aos $10 \mathrm{~min}(\mathrm{~m} 10)$ e aos $90 \mathrm{~min}(\mathrm{~m} 90)$, em gramas. Obteve-se os resultados de absorção de água por capilaridade (Figura $6^{\text {a }}$ ) e os coeficientes de capilaridade (Figura 6b). 
a)

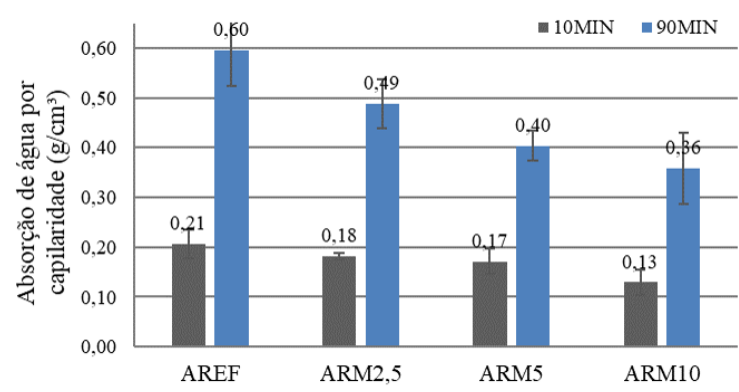

b)

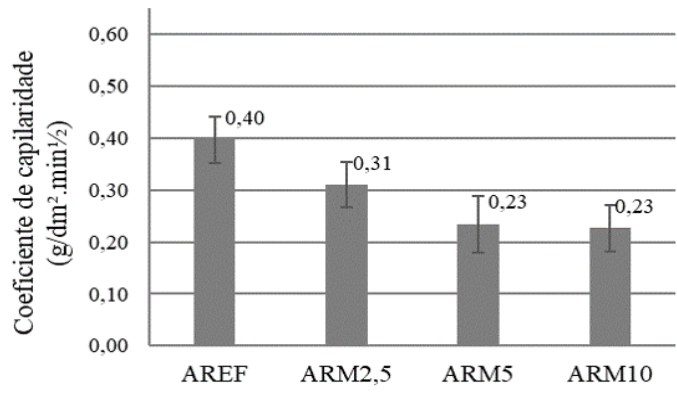

Figura 6: (a) Absorção de água por capilaridade aos 10 e aos 90 minutos, (b) Coeficiente de capilaridade.

A partir da Figura 6, observa-se que todos os traços com substituição da areia por serragem de madeira sofreram uma redução na absorção de água por capilaridade aos 10 e 90 min, assim como em seu coeficiente de capilaridade. Esta redução dos valores também foi observada nos estudos de BOUGUERRA et al. [19], no qual o referido autor concluiu em sua pesquisa que a adição de agregados macro porosos, como é o caso dos agregados de madeira, reduz a absorção capilar no interior da argamassa. Conforme RATO [47] o coeficiente de absorção de água por capilaridade depende de fatores como a quantidade de poros, conectividade da rede porosa e a dimensão dos poros, sendo que, quanto menor for o tamanho dos poros maior serão as forças capilares. Segundo Martinho [1] a inserção de resíduos porosos, como ocorre com a serragem de madeira, sendo que esses poros podem ser considerados macro poros [19], dado as suas dimensões, reduzem a absorção capilar das argamassas, pois originam redes capilares de grandes dimensões e, assim, diminuem o fluxo de água no interior da argamassa por minimizar as forças de sucção.

Após analisar estatisticamente, pode-se afirmar com 95\% de confiabilidade que há uma diferença significativa na absorção de água aos 10 min entre as misturas AREF e ARM10,0 e uma diferença significativa na absorção de água aos 90 min entre o traço AREF e os traços ARM5,0 e ARM10,0. No traço ARM10,0 reduziu-se a absorção de água em 37,38\% aos 10 min e 39,93 \% aos 90 min e no traço ARM5 houve uma redução de 32,21\% aos 90 min. Quanto ao coeficiente de capilaridade há uma diferença significativa entre os traços ARM5,0 e ARM10,0 em relação a AREF, atestando uma redução de 57,5\%.

Foi determinada a massa específica real no estado endurecido e ao comparar os valores médios obtidos no ensaio, conforme apresenta a Tabela 2, verificou-se que quanto maior o percentual de substituição de areia por serragem, menores são as massas específicas das argamassas. Entretanto, ao realizar a ANOVA de fator único, observou-se que não há diferença significativa entre as composições ARM2,5 e ARM10,0 em relação a argamassa referência, somente a ARM10,0 difere-se estatisticamente dos demais traços. Tal fato pode ser justificado pelo maior percentual de substituição da ARM10,0 em relação aos demais traços. Esse resultado difere-se do encontrado por GARCEZ et al. [5], que não observaram diferença estatística na massa especifica real em relação a composição de referência ao substituir 10 e $20 \%$ da areia por serragem de madeira. Já, para o índice de vazios percebe-se que a AREF apresentou média inferior a ARM2,5, no entanto sem diferença significativa, conforme ANOVA realizada. Ainda, de acordo com a ANOVA, pode-se afirmar que a única diferença significativa verificada foi entre os traços ARM2,5 e ARM10,0, apesar de observar-se que a partir de ARM2,5 tem-se valores médios de índice de vazios com tendência a elevar-se.

Tabela 2: Resultados dos ensaios de massa específica e índice de vazios

\begin{tabular}{lcccc}
\hline & \multicolumn{2}{c}{ Massa específica real } & \multicolumn{2}{c}{ Índice de vazios } \\
$\left(\mathrm{g} / \mathrm{cm}^{3}\right)$ & \multicolumn{2}{c}{$(\%)$} \\
\cline { 2 - 5 } Traço & \multicolumn{2}{c}{ Média } & Desvio padrão & Média \\
& $\left(\mathrm{g} / \mathrm{cm}^{3}\right)$ & $\left(\mathrm{g} / \mathrm{cm}^{3}\right)$ & $\begin{array}{c}\text { Desvio padrão } \\
(\%)\end{array}$ & $(\%)$ \\
\hline AREF & 2,46 & 0,00 & 16,54 & 0,56 \\
ARM2,5 & 2,44 & 0,01 & 15,99 & 0,42 \\
ARM5,0 & 2,38 & 0,00 & 17,70 & 0,51 \\
ARM10,0 & 2,36 & 0,00 & 18,21 & 0,31 \\
\hline
\end{tabular}


Com objetivo de analisar as propriedades mecânicas de cada tipo de argamassa, foram determinadas as resistências à tração na flexão e resistências à compressão axial. Os resultados obtidos nos respectivos ensaios podem ser observados na Tabela 3.

Tabela 3: Resultados dos ensaios de tração na flexão e de compressão axial

\begin{tabular}{|c|c|c|c|c|}
\hline \multirow{2}{*}{ Traço } & \multicolumn{2}{|c|}{$\begin{array}{l}\text { Resistência a tração na flexão } \\
\text { (MPa) }\end{array}$} & \multicolumn{2}{|c|}{$\begin{array}{c}\text { Resistência a compressão axial } \\
\text { (MPa) }\end{array}$} \\
\hline & Média (MPa) & $\begin{array}{l}\text { Desvio padrão } \\
\text { (MPa) }\end{array}$ & Média (MPa) & $\begin{array}{c}\text { Desvio padrão } \\
\text { (MPa) }\end{array}$ \\
\hline AREF & 3,32 & 0,52 & 11,30 & 0,72 \\
\hline ARM2,5 & 2,44 & 0,10 & 10,50 & 0,61 \\
\hline ARM5,0 & 3,32 & 0,23 & 11,90 & 0,79 \\
\hline ARM10,0 & 3,26 & 0,28 & 9,940 & 0,58 \\
\hline
\end{tabular}

Conforme observa-se na Tabela 3, o valor médio de resistência à tração na flexão do traço ARM5,0 mostrou-se similar ao traço AREF, enquanto o valor médio de resistência a compressão axial do mesmo traço mostrou-se superior ao AREF. A mistura ARM2,5 foi a que apresentou menor valor de resistência a tração na flexão e a mistura ARM10,0 o menor valor de resistência a compressão axial.

Ao realizar a análise estatística de fator único, pode-se afirmar com $95 \%$ de confiança que há diferença significativa entre os valores de resistência a tração na flexão do traço AREF e ARM2,5, fato que pode estar relacionado ao maior valor do desvio padrão do AREF em comparação aos demais traços.

Com base na análise estatística referente ao ensaio de compressão axial pôde-se constatar que não há diferença significativa entre os resultados obtidos em relação ao AREF. Entretanto, esse valor mínimo de compressão axial da mistura ARM10,0 é válido quando confrontado com a pesquisa realizada por CORINALDESI, MAZZOLI e SIDDIQUE [4] e GIL, ORTEGA e PÉREZ [6], em que seus valores de resistência à compressão de argamassas com 10\% de resíduos também exibiram os menores valores médios perante os traços com menor percentual de serragem. GARCEZ et al [5] afirmam que a incorporação do resíduo de madeira tende a gerar um compósito com menor densidade e, consequentemente, menor resistência à compressão. Percebe-se, com base nos resultados dessa pesquisa que tal afirmação trata-se de uma possível tendência, tendo em vista, que a composição ARM10,0 apresentou menores médias de massa específica real e resistência à compressão e maior índice de vazios. Contudo, cabe mencionar que a resistência à compressão axial não é preponderante em argamassas, sendo que as características de retenção de água e absorção de água por capilaridade, por exemplo, são mais importantes.

O resultado do ensaio empírico sobre a capacidade de isolamento térmico de cada composição está apresentado no gráfico da Figura 7. Considerou-se o sistema com melhor isolamento térmico aquele com maior diferença entre a face externa do painel e a temperatura interna da estufa.

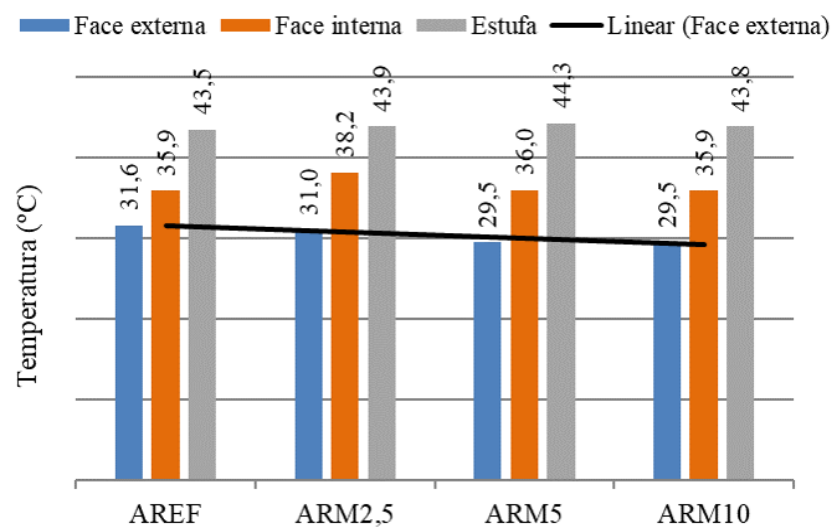

Figura 7: Média das temperaturas do ensaio de isolamento térmico dos painéis

Os resultados do ensaio demonstraram que as misturas com inserção de resíduo de madeira apresenta- 
ram diferença de temperatura entre a face externa do painel e a estufa superiores e também entre as faces do painel quando confrontados com o traço AREF. Analisando a linha de tendência, observa-se a redução gradual da temperatura da face externa, conforme aumenta o teor de resíduo de madeira inserido. Dentre as três misturas com substituição do agregado miúdo por resíduo de madeira, a ARM5,0 foi a que apresentou maior variação de temperatura entre a face externa e a estufa, enquanto a ARM2,5 demonstrou maior diferença entre as faces do painel.

\section{CONCLUSÕES}

Diante dos resultados obtidos e analisados pode-se constatar que as características das argamassas com substituição do agregado miúdo por resíduo de madeira, indiferente ao percentual de substituição, apresentaram valores adequados para uso na construção civil.

Os resultados de retenção de água tendem a aumentar com o aumento do percentual de inserção da serragem de madeira, quesito positivo, considerando-se que maior será a força da argamassa em reter a água na mistura. Já, o índice de consistência apresentou tendência a diminuir com o aumento do resíduo na mistura, no entanto, até o percentual máximo pesquisado de 10,0\% essa redução não é prejudicial as aplicações da argamassa na construção civil. Fato semelhante observa-se com a densidade de massa no estado fresco, ou seja, diminuição dos valores com maior incremento de resíduo de madeira na composição, no entanto, sem apresentar valores que possam afetar as funções das argamassas.

Com base nos valores obtidos nos ensaios realizados no estado endurecido (absorção de água por capilaridade, coeficiente de capilaridade, massa específica real, índice de vazios, resistência à compressão e à tração na flexão) pode-se afirmar que os resultados são promissores. Quanto maior o percentual de resíduos de madeira empregado menores os valores de absorção de água por capilaridade e coeficiente de capilaridade com tendência também em apresentar menores valores de massa específica real e resistências mecânicas. Sendo que, esse último, não se trata de uma propriedade preponderante das argamassas.

De acordo com o ensaio de isolamento térmico novamente obteve-se resultados interessantes pois todas as composições com inserção de resíduo de madeira apresentaram um melhor isolamento térmico em relação a AREF.

\section{BIBLIOGRAFIA}

[1] MARTINHO, P.A.G., "Análise do comportamento de argamassas com a incorporação de "pellets" de madeira", Dissertação M.Sc (Mestrado em Engenharia Civil), Faculdade de Ciências e Tecnologia da Universidade Nova de Lisboa, Lisboa, 2017. Disponível em: http://hdl.handle.net/10362/23409. Acesso em: Maio de 2018.

[2] BEDERINA, M., LAIDOUDI, B., GOULLIEUX, A., et al.,"Effect of the treatment of wood shavings on the physico-mechanical characteristics of wood sand concretes", Constr. Build. Mater. v. 23, n. 3, pp. 13111315,2009

[3] CORRÊA, L.R., "Sustentabilidade na construção civil”, Monografia (Especialização em Construção Civil) - Escola de Engenharia da UFMG, Belo Horizonte, 2009.

[4] CORINALDESI, V., MAZZOLI, A., SIDDIQUE, R., "Characterization of lightweight mortars containing wood processing by-products waste", Construction and Building Materials, v. 123, pp. 281-289, 2016.

[5] GARCEZ, M.R., SANTOS, T., GARCEZ E.O., et al., "Propriedades físicas de compósitos cimentomadeira com serragem de Pinus elliottii tratada", Revista Ciência da Madeira (Brazilian Journal of Wood Science), v. 7, n. 2, 2016.

[6] GIL, H., ORTEGA, A., PÉREZ, J. "Mechanical behavior of mortar reinforced with sawdust waste", Elsevier BV. http://dx.doi.org/10.1016/j.proeng.2017.07.046. Procedia Engineering, [s.1.], v. 200, pp. 325-332, 2017.

[7] BITENCOURT, S.S., et al. "Desenvolvimento de biocompósitos de poli(L-ácido láctico) (PLLA) com serragem de madeira", FapUNIFESP (SciELO). http://dx.doi.org/10.1590/s1517-707620170004.0233. Matéria (Rio de Janeiro), [s.l.], v. 22, n. 4, out. 2017.

[8] AIGBOMIAN, E.P., FAN, P., "Development of wood-crete from treated sawdust", Constr. Build. Mater. v. 52, pp. 353-360, 2014.

[9] ASSOCIAÇÃO BRASILEIRA DA INDÚSTRIA DE MADEIRA PROCESSADA MECANICAMENTE (ABIMCI) (Paraná). Estudo Setorial em Síntese: Séries históricas até 2016 exportações janeiro a junho de 2017. Parana: Abimc, 2017. 19 p. 
[10] INDÚSTRIA BRASILEIRA DE ÁRVORES (IBÁ) (São Paulo) (Org.). Relatório 2019. São Paulo: Studio 113, 2019. $80 \mathrm{p}$.

[11] FAGUNDES, H.A.V. "Diagnóstico da produção de madeira serrada e geração de resíduos do processamento de madeira de florestas plantadas no Rio Grande do Sul”. 2003. 180p. Dissertação (Mestrado em Engenharia Civil) - Universidade Federal do Rio Grande do Sul, Porto Alegre.

[12] CADORIN, Vilson. Análise da viabilidade de utilização de resíduos de madeira na produção de painéis de madeira aglomerada. 2008. 46 p. TCC (Engenharia civil) Univ. do Extremo Sul Catarinense - UNESC, Criciúma.

[13] ABNT NBR 10004, “Resíduos sólidos: classificação”, 2004.

[14] WIECHETECK, M. "Aproveitamento de resíduos e subprodutos florestais, alternativas tecnológicas e propostas de políticas ao uso de resíduos florestais para fins energéticos". Projeto PNUD BRA 00/20-Apoio às Políticas Públicas na Área de Gestão e Controle Ambiental, 2009.

[15] ZENID, J. G., "Madeira na Construção Civil", Instituto de Pesquisas Tecnológicas do Estado de São Paulo, São Paulo, 2011.

[16] OLIVEIRA, L. A. de., "Conforto térmico em edificações", Dissertação M.Sc, Universidade Estadual Paulista, Faculdade de Engenharia de Guaratinguetá, 2003. Disponível em: http://hdl.handle.net/11449/99347. Acesso em: 30 Mar. 2018.

[17] ABNT NBR 15575-1, "Edificações Habitacionais - Desempenho - Parte 1: Requisitos gerais", 2013.

[18] COTA, S. M. A., “Análise energética de um edifício público”, Dissertação M.Sc, (Mestrado em Energias Renováveis e Eficiência Energética) - Escola Superior de Tecnologia e de Gestão Instituto Politécnico de Bragança, 2014.. Disponível em: http://hdl.handle.net/10198/10320. Acesso em: Março de 2018.

[19] BOUGUERRA, A. et al, "Water Sorptivity and Pore Structure of Wood Cementitious Composites", Magazine Concrete Research, v. 54, v. 2, p. 103-112, 2002.

[20] TAMBA, S., JAUBERTHIE, R., LANOS, C., RENDELL, F., "Lightweight wood fibre concrete". Concr Sci Eng., v. 3, pp. 53-7, 2001.

[21] ARRUDA, P.P., SILVA, A.O., MARTINEZ, R.G., "Utilização de resíduos de madeira como elemen-to construtivo', In: Encontro Nacional de Tecnologia do Ambiente Construído, 14, Minas Gerais. Anais eletrônicos, Minas Gerais: Entec, 2012. Disponível em: http://www.infohab.org.br/entac2014/2012/docs/0592.pdf . Acesso em: 12 mar. de 2018.

[22] DANTAS F.F.P., "Contribuição ao estudo para aplicação do pó de serra da madeira em elementos de alvenaria de concreto não estrutural", Dissertação M.Sc, Curso de Engenharia Civil, Faculdade de Engenharia Civil, Arquitetura e Urbanismo da Universidade, Universidade Estadual de Campinas, Campinas, 2004. Disponível em: http://repositorio.unicamp.br/jspui/handle/REPOSIP/258507 . Acesso em: 15 mar. 2018.

[23] BELHADJ, B., BEDERINA, M., MONTRELAY, N., et al. "Effect of substitution of wood shavings by barley straws on the physico-mechanical properties of lightweight sand concrete", Constr. Build. Mater. 66 (2014) 247-258.

[24] BEDERINA, M., MARMORET, L., MEZREB, K., et al. "Effect of the addition of wood shavings on the thermal conductivity of the sand concretes - experimental study and modelling", Constr. Build. Mater. v. 21, n.3, pp. 662-668, 2007.

[25] PEHANICH, J.L., BLANKENHORN, P.R., SILSBEE, M.R., "Wood fiber surface treatment level effects on select mechanical properties of wood fiber-cement composite". Cement Concr Res, v. 34, pp. 59-65, 2004.

[26] CECHIN, Luana, "Análise da viabilidade de produção de painéis de cimento reforçados com biomassa ve-getal e escória de alto-forno", Dissertação M.Sc, Universidade Tecnológica Federal do Paraná, Curitiba, 2017.

[27] IZQUIERDO, I.S. Uso de fibra natural de sisal em blocos de concreto para alvenaria estrutural. 201. 128 f. Dissertação (Mestrado) Curso de pós-graduação de Engenharia de Estruturas, Escola de Engenharia de São Carlos, Universidade de São Paulo. São Paulo, 2011.

[28] MOUBARIK A., GRIMI N., BOUSETTA N. Stuctural and thermal characterization of Moroccan sugar cane bagasse cellulose fibers and their applications as a reinforcing agent in low density polyethylene. Composi-tes: Part B, 2013. 
[29] VILPERT, G.C., "Telha de Concreto: Adição de fibra derivada de bagaço de cana-de-açúcar”. 2018. 19p. TCC (Engenharia civil) Univ. do Extremo Sul Catarinense - UNESC, Criciúma.

[30] PELLEGRIN, M.Z. "Desenvolvimento de um compósito argamassa/celulose de cana-de-açúcar". 2017. 93 f. Dissertação (Mestrado) Curso de pós-graduação de engenharia de materiais, Universidade do Extremo Sul Catarinense, Criciúma, 2017.

[31] TITA, S., PAIVA, J., FROLLINI, E. Resistência ao impacto e outras propriedades de compósitos lignocelulósicos: Matrizes termofixas fenólicas reforçadas com fibras de bagaço de cana-de-açúcar. Polímeros: Ciência e Tecnologia, v. 12, n. 4, p. 228-239, 2002.

[32] GUPTA, S., HARN, W.K., KOH, H.J. "Application of biochar fromfood and wood waste as green admixture for cement mortar", Elsevier BV. http://dx.doi.org/10.1016/j.scitotenv.2017.11.044. Science of the Total Environment, [s.1.], v. 619-620, pp.419-435, abr. 2018.

[33] ACIU, C., TAMAS-GAVREA, R., MUNTEANU, C. "Manufacture of Ecological Mortars by Cork and Sawdust Waste Recycling”, Bull. Univ. Agric. Sci. Vet. Med. Cluj-Napoca Hortic. 70 (2013).

[34] ABNT NBR NM 248, "Agregados - Determinação da composição granulométrica”, 2003.

[35] ABNT NBR NM 45, "Agregados - Determinação da massa unitária e do volume de vazios", 2006.

[36] ABNT NBR 16541, "Argamassa para assentamento e revestimento de paredes e tetos - Preparo da mistura para a realização de ensaios", 2016.

[37] ABNT NBR 13276, “Argamassa para assentamento e revestimento de paredes e tetos - Determinação do índice de consistência”, 2016.

[38] ABNT NBR 13277, "Argamassa para assentamento e revestimento de paredes e tetos - Determinação da retenção de água", 2005.

[39] ABNT NBR 13278, "Argamassa para assentamento e revestimento de paredes e tetos - Determinação da densidade de massa e do teor de ar incorporado", 2005.

[40] ABNT NBR 13279, "Argamassa para assentamento e revestimento de paredes e tetos - Determinação da resistência à tração na flexão e à compressão”, 2005.

[41] ABNT NBR 15259, "Argamassa para assentamento e revestimento de paredes e tetos - Determinação da absorção de água por capilaridade e do coeficiente de capilaridade", 2005.

[42] ABNT NBR 9778, "Argamassa e concreto endurecidos - Determinação da absorção de água, índice de vazios e massa específica", 2005.

[43] FORMOSA J., CHIMENOS J.M., LACASTA A.M., et al., "Novel fire-protecting mortars formulated with magnesium by-products", Cement and Concrete Research, v. 41, n. 2, p. 191-196, 2011.

[44] CINCOTTO, M.A., SILVA, M.A.C., CARASEK, H, "Argamassas de revestimento: características, propriedades e métodos de ensaio", Instituto de Pesquisas Tecnológicas, (Boletim 68 IPT), São Paulo, 1995.

[45] FERRARI, S., PEREIRA, E.; VITO, M., et al., "Análise da retenção de água em argamassas colantes de mercado", In: Simpósio Brasileiro de Tecnologia das Argamassas, 12, Belo Horizonte, Minas Gerais: GT Argamassas, 2011.

[46] LIMA, A.J.M., IWAKIRI, S., "Utilização de resíduos da madeira de pinus spp. como substituição ao agregado miúdo na produção de blocos de concreto para alvenaria estrutural". Ciência Florestal, vol.24, n.1, pp.223-235, 2014.

[47] RATO, V.N.P.M., "Influência da microestrutura morfológica no comportamento de argamassas", Tese D. Sc, Curso de Engenharia Civil, Faculdade de Ciências e Tecnologia, Universidade Nova de Lisboa, Lisboa, 2006. Disponível em: <http://hdl.handle.net/10362/1126>. Acesso em: 18 Nov. 2018.

\section{ORCID}

Jussara Adílio da Silva

Elaine Guglielmi Pavei Antunes

Jorge Henrique Piva

Aline Eyng Savi

Augusto Wanderlind https://orcid.org/0000-0002-0151-6792

https://orcid.org/0000-0002-9698-1100

https://orcid.org/0000-0002-1753-4944

https://orcid.org/0000-0002-6114-8725

http://orcid.org/0000-0002-5312-9700 